\title{
The dreaded osteonecrosis of femur following chronic steroid therapy: a case series from a dermatologist's eye
}

\author{
Abiram Ponnuswami*, Cordelia Babitha S., Krishnakanth Muralidhar, Murugan Sundaram
}

Department of Dermatology, Sri Ramachandra Institute of Higher Education and Research, Porur, Chennai, India

\author{
Received: 30 November 2019 \\ Revised: 03 February 2020 \\ Accepted: 04 February 2020

\section{*Correspondence:} \\ Dr. Abiram Ponnuswami, \\ E-mail: here.abi@gmail.com
}

Copyright: ( ) the author(s), publisher and licensee Medip Academy. This is an open-access article distributed under the terms of the Creative Commons Attribution Non-Commercial License, which permits unrestricted non-commercial use, distribution, and reproduction in any medium, provided the original work is properly cited.

\begin{abstract}
Corticosteroids, undoubtedly, is the saving grace of many patients ailing from a variety of inflammatory and autoimmune dermatoses. But it is not free of side effects, some being crippling enough to subject the patient to huge amounts of morbidity. Here we report a series of cases - Vesiculobullous diseases and Lupus Erythematosus - with prolonged oral steroid therapy that lead to osteopenia and osteonecrosis of the femur.
\end{abstract}

Keywords: Avascular necrosis of femur, Osteopenia, Chronic steroid usage, DEXA scan

\section{INTRODUCTION}

Corticosteroid therapy, irrespective of the mode of administration, systemic- oral or parenteral or topical therapy - has its own associated risks of side-effects. Avascular necrosis of the femoral head is one of the universally recognized side-effects of steroid therapy. ${ }^{1}$ The etiology of avascular necrosis is multifactorial and ranges from fracture of the neck of femur to traumatic dislocation of hip to slipped femoral capital epiphysis. ${ }^{2,3}$ It has been reported to occur secondary to osteotomy, sickle cell anemia, alcoholism, autoimmune connective tissue disorder like rheumatoid arthritis, lupus erythematosus, pancreatitis, occlusive vascular disease, pheochromocytoma, infections, radiation, Gaucher's disease, renal transplantation, Caisson's disease and even in pregnancy. ${ }^{4-7}$

Amongst the dermatological diseases, avascular necrosis of the femoral head has been reported more commonly in SLE, Psoriasis, Pemphigus - secondary to even potent topical corticosteroids such as clobetasol cream. ${ }^{7,8}$
Avascular necrosis manifests clinically as insidious onset of pain, aggravated by movements, relieved by rest, with occasional radiation down the affected limb. A slight limp, often unilateral, with limitation of abduction and adduction movements to a variable degree is characteristic. Atrophy of the proximal muscles may be seen. Femoral head has a precarious blood supply leading to a wedge-shaped area of avascular necrosis. Necrosis radiologically appears as a mottled area and the fibrous zone as a radiolucent band with demineralization of the uninvolved bone. ${ }^{9}$

The pathophysiological mechanisms include increase in the intra-osseous pressure resulting from lipocyte hypertrophy, deposition of fat in the marrow spaces of the skeleton in patients who were treated with steroids, particularly in individuals who underwent short-term treatment with high-dose steroids, blood stasis and ischemia in the trabecular bone, increase in the osteocyte apoptosis owing to micro damage in the bone could have a role too. ${ }^{10-13}$ Whatever be the pathologic etiology, so far, an exact relationship between the dose and the mode of administration, and the risk of developing avascular necrosis, has not been determined. 


\section{CASE REPORTS}

\section{Case 1}

A 39 years old female, a known case of Pemphigus vulgaris, on prolonged steroid therapy for one year and six months, due to periodic exacerbations, comes with complaints of right sided hip pain. She was initially on 40 $\mathrm{mg} /$ day prednisolone which was then tapered and currently on $10 \mathrm{mg} / \mathrm{day}$. On obtaining opinion from the orthopaedician and evaluating with the bone mineral density and DEXA scan, osteopenia and osteonecrosis was diagnosed in the right hip joint (Figure 1).

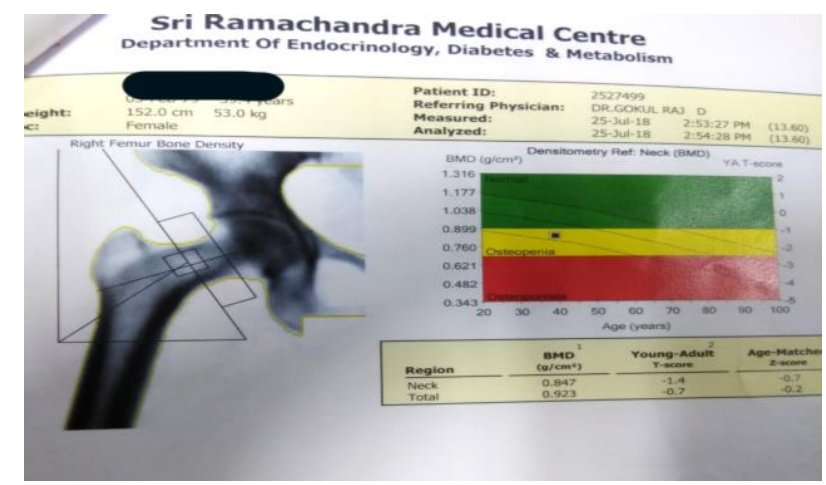

Figure 1: Osteonecrotic changes in the right hip joint.

\section{Case 2}

A 44 years old female, a known case of Pemphigus foliaceous for the past 1 year, comes with complaints of left sided hip pain for the past six months. She was initially on $40 \mathrm{mg} /$ day prednisolone which was tapered and now currently on $10 \mathrm{mg} / \mathrm{day}$ prednisolone on alternate days. Orthopaedician opinion was sought and following investigations, osteonecrosis of left hip joint was made (Figure 2).

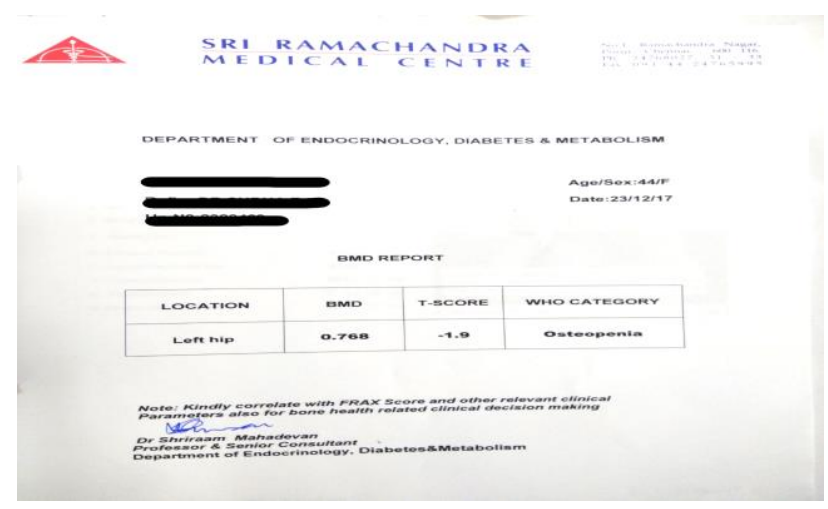

Figure 2: Bone mineral density showing osteopenic changes.

\section{Case 3}

A 39 years old female with discoid lupus erythematosus on prolonged oral steroid therapy, presented with restriction of movements of bilateral hip joints. She was irregular on follow up and kept consuming $10 \mathrm{mg} /$ day prednisolone for the past six months. Based on bone mineral density and DEXA scan, avascular necrosis of left hip joint and osteopenia of right hip joint was made (Figure 3).

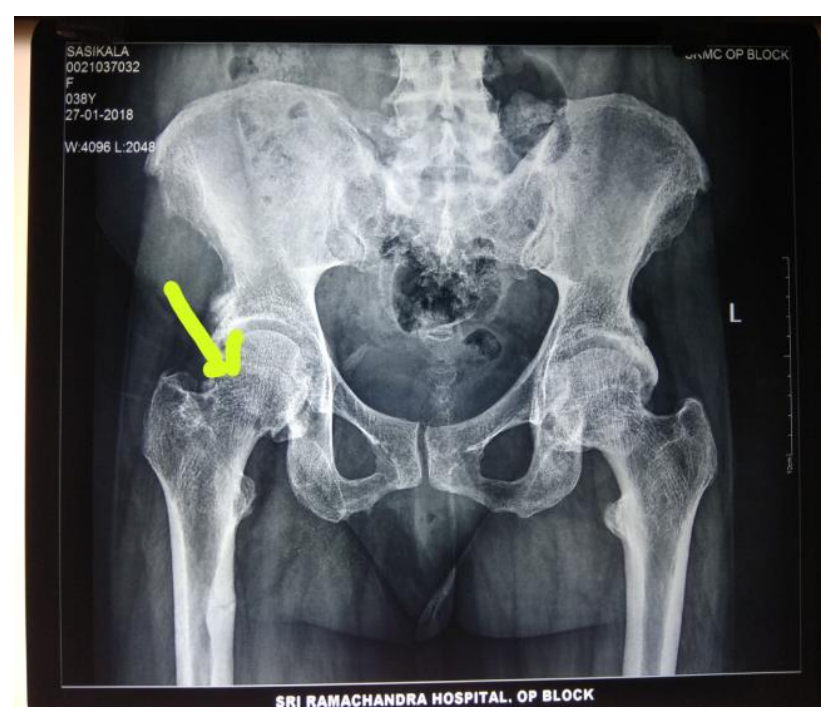

Figure 3: Right hip joint showing osteopenic changes.

\section{Case 4}

A 39 years old homemaker with Pemphigus vulgaris, with unsupervised steroid intake for 3 years, reports with pain in hip joint on both sides. Following DEXA scan, osteonecrosis of both hip joints was made (Figure 4).

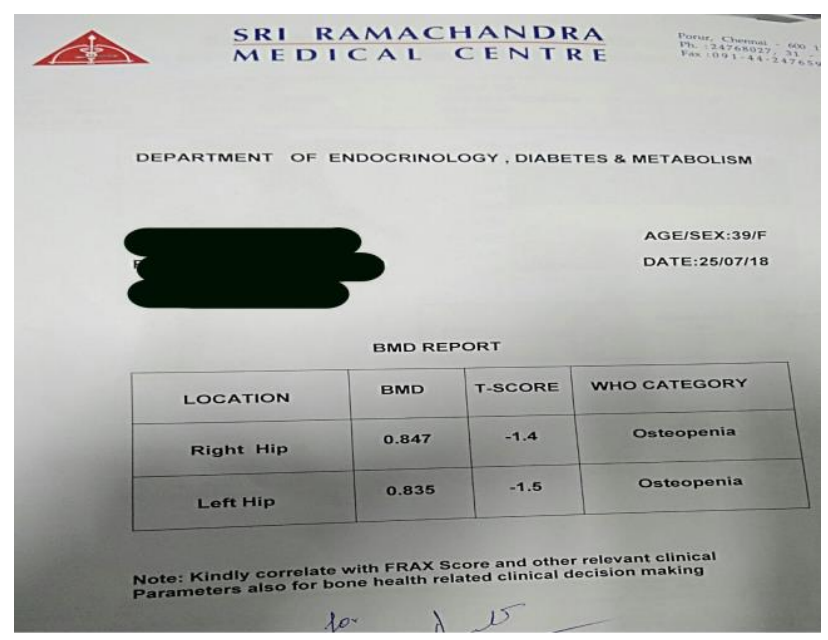

Figure 4: Bone mineral density report showing osteopenia of bilateral hip joints.

\section{DISCUSSION}

The first patient of pemphigus (described by Pietrogrande and Mastronmarino), was a woman, who developed avascular necrosis after four years of therapy with 100 mg cortisone acetate daily. ${ }^{10}$ 
The risk factors for avascular necrosis of femur include: high dose systemic steroids, chronic alcoholism, smoking and hip dislocations and fracture.

It is useful to note that steroids greater than $10 \mathrm{mg} /$ day for 6 months or equivalent, can cause osteonecrosis. Also, osteoporotic changes can start as early as 2 months with $20 \mathrm{mg}$ dose. Certain risk factors pertaining to the particular disease entity might enhance the risk e.g., hyperuricemia in psoriatics, hyperlipidemias in SLE etc. ${ }^{8}$

Candidates requiring monitoring include those who require steroids for $>3$ months or $10 \mathrm{mg} /$ day for 6 months or equivalent. ${ }^{10}$

According to the American College of Rheumatology guidelines (2017), steps to prevent AVN include: BMD of lumbar spine/hip - before initiating therapy, BMD of lumbar spine/ hip - every 6 months, BMD every year - if preventive measures are undertaken, calcium - 1000 to $1500 \mathrm{mg} /$ day, vitamin D3 - 800 IU/day, gonadal hormones - oestrogen, SERM - raloxifene $60 \mathrm{mg} / \mathrm{day}$, bazedoxifene 20 to $40 \mathrm{mg} /$ day, bisphosphonates alendronate $10 \mathrm{mg} /$ day, ibandronate $2 \mathrm{mg} /$ day, thiazides and sodium restriction, calcitonin - 200 IU/week and anabolic steroids (second line). ${ }^{9}$

Amongst the non-traumatic causes of avascular necrosis of the femur, patients of SLE who are treated with corticosteroids have been reported to have a high relative risk of developing avascular necrosis with a reported frequency of $5-40 \% .^{14}$

One study in SLE patients reviewed the clinical features of the disease and the laboratory data of the patients of SLE at the time of developing avascular necrosis and the dose of steroids and found that a rash introduction of high-dose steroids (>30 g/day) prednisolone without "steroid preloading" was associated with a higher risk of avascular necrosis and suggested that a minimum/ moderate amount of glucocorticoid preloading lessens the risk of avascular necrosis. ${ }^{15}$

\section{CONCLUSION}

Systemic corticosteroids entail increased risk of developing osteonecrosis with cases being reported as early as 12 months into steroid therapy (on an average dose of $20 \mathrm{mg}$ steroids). Hence it is important to monitor steroid regimen judiciously and switch over to steroid sparing agents promptly. Calcium and bisphosphonates supplementation, restriction of weight bearing and periodic bone mineral density and radiological checkup are of paramount importance.

Funding: No funding sources Conflict of interest: None declared Ethical approval: Not required

\section{REFERENCES}

1. Banks HH. Factors influencing the result in fractures of the femoral neck. J Bone Joint Surg Am. 1962;44:931.

2. Smith FB. Effects of rotary and valgus malposition on the blood supply to femoral head. J Bone Joint Surg Am. 1959;41:800.

3. Garden RS. Low angle fixation in the fractures of the femoral neck. J Bone Joint Surg. 1961;313:647.

4. Brav EA. Traumatic dislocation of the hip: Army experience and results over a twelve year period. J Bone Joint Surg Am. 1962;44:1115.

5. Lowe HG. Avascular necrosis after slipping of the upper femoral epiphysis. J Bone Joint Surg Br. 1961;43:688.

6. Herndon JH, Autranc OE. Avascular necrosis of the femoral head in the adult: A review of its incidence in a variety of conditions. Clin Orthop Relat Res. 1972;86:43-62.

7. Bergstein JM, Wiens C, Fish AJ, Veinier RL, Michael A. Avascular necrosis of bone in systemic lupus erythematosus. J Pediatr. 1974;85:31-5.

8. Compston J. Glucocorticoid-induced osteoporosis: an update. Endocrine. 2018;61(1):7-16.

9. van Staa TP, Leufkens HG, Abenhaim L, Begaud S, Zhang B, Cooper C. Use of oral corticosteroids in the United Kingdom. Q Med J. 2000;93:105-11.

10. Fardet L, Petersen I, Nazareth I. Prevalence of longterm oral glucocorticoid prescriptions in the UK over the past 20 years. Rheumatology. 2011;50(11):1982-90.

11. Epstien NN, Tuffanelli DL, Epstein JH. Avascular bone necrosis: A complication of long terms corticosteroid therapy. Arch Dermatol. 1965;92:170-80.

12. Shim SS, Hawk HE, Yu WY. The relationship between blood flow and cavity pressure of bone. Surg Gynaecol Obstet. 1972;135:353-60.

13. Zizic TM, Hungerford DS, Stevens HB. Ischaemic bone necrosis in systemic lupus erythematosus: 1, The early diagnosis of ischaemic necrosis of bone. Medicine. 1980;59:134-42.

14. Felson DT, Anderson JJ. A cross study evaluation of association between steroid dose and bolus steroids and vascular necrosis and avascular necrosis of the bone. Lancet. 1987;1:902-6.

15. Manolagas SC, Weinstein RS. New developments in the pathogenesis and treatment of steroid induced osteoporosis. J Bone Miner Res. 1999;14:1061-6.

Cite this article as: Ponnuswami A, Cordelia BS, Muralidhar K, Sundaram M. The dreaded Osteonecrosis of Femur following chronic steroid therapy. Int J Res Dermatol 2020;6:264-6. 